\title{
К ВОПРОСУ ОБ ИНДИКАТОРАХ КОРРУПЦИИ В СИСТЕМЕ ГОСУДАРСТВЕННОЙ И МУНИЦИПАЛЬНОЙ СЛУЖБЫ
}

\begin{abstract}
Аннотация. Предметом статьи являются проблемы формирования перечня индикаторов, отражающих динамику и характер коррупционных правонарушений в системе государственной и муниципальной службы. В статье анализируются существующие подходы к измерению уровня коррупции с учетом международной и отечественной практики. Основное внимание в статье уделяется классификации индикаторов, основанных на коррупционных правонарушениях, выявленных подразделениями по профилактике коррупции органов государственной власти и местного самоуправления. Данные правонарушения относятся к категории дисциплинарных проступков, предлагаемые индикаторы отражают уровень антикоррупционной дисциплины в органах государственной власти и местного мамоуправления $B$ статье применялись общефилософские методы (системный метод, анализ, синтез, аналогия), традиционно правовые методы (формально-логический), а также статистические методы. Основной вывод, сформулированный автором, заключается в необходимости связи индикаторов коррупции с формированием антикоррупционной политики в органе власти и оценкой эффективности проводимых антикоррупционных мероприятий, что соответствует методологии, разработанной Счетной палатой РФ. Новизна статьи заключается в разработке предложений по применению индикаторов коррупции для выработки и (или) корректировки адресных мер по противодействию коррупции в органе государственной власти или органе местного самоуправления.
\end{abstract}

Ключевые слова: государственная служба, муниципальная служба, коррупция, индикатор, латентность, коррупционная пораженность, коррупционный охват, антикоррупционная политика, адресность, эффекmивность.

Review. The subject of the article is the process of formation of a set of indicators reflecting dynamics and character of corruption offences in the system of public and municipal service. The author analyzes the existing approaches to the assessment of corruption level taking into account the international and Russian practice. The main attention is paid to the classification of indicators based on corruption crimes revealed by corruption prevention units of public and local authorities. These offences rate among disciplinary delinquencies, and the proposed indicators reflect the level of anticorruption discipline in public and local authorities. The author applies general philosophical methods (the systems method, analysis, synthesis, analogy), traditional legal methods (formal-logical) and statistical methods. The author concludes that it is necessary to connect corruption indicators with the formation of anticorruption policy and efficiency assessment of anticorruption measures, which corresponds with the methodology developed by the Audit Chamber of the Russian Federation. The novelty of the research lies in the development of suggestions about the application of corruption indicators for development and (or) correction of targeted anticorruption measures in public or local authorities.

Key words: public service, municipal service, corruption, indicator, latency, susceptibility to corruption, corruption scale, anticorruption policy, targeted character, efficiency.

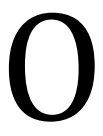
рганизация противодействия коррупции в системе государственной и муниципальной службы предполагает реализацию адресной антикоррупционной политики, основанной на оценке ключевых показателей, характеризующих коррупцию как социально-правовое явление к конкретной сфере, отрасли, сегменте публичного управления, в конкретном органе власти. 


\section{Административное и муниципальное право 12 (96) • 2015}

Показатели и индикаторы коррупционных нарушений в мировой практике противодействия коррупции основаны на применении интегрированных индексов, наиболее известными из которых являются индекс восприятия коррупции и индекс взяткодателей[1].

Конвенция ООН против коррупции [2]в ст. 61 определяет обязанности государств-участников этой конвенции по сбору и анализу информации о коррупции и обмену такой информацией. В частности, каждое Государство-участник рассматривает возможность проведения, в консультации с экспертами, анализа тенденций в области коррупции на своей территории, а также условий, в которых совершаются коррупционные правонарушения. Государства-участники, с целью разработки, насколько это возможно, общих определений, стандартов и методологий, рассматривают возможность расширения статистических данных, аналитических знаний относительно коррупции и информации, в том числе об оптимальных видах практики в деле предупреждения коррупции и борьбы с ней, и обмена ими между собой и через посредство международных и региональных организаций. Каждое Государство-участник рассматривает возможность осуществления контроля за своей политикой и практическими мерами по борьбе с коррупцией, а также проведения оценки их эффективности и действенности.

В соответствии с обязательствами, возложенными Россией в связи с ратификацией данной Конвенции, системные исследования коррупции проводит международная организация Центр антикоррупционных исследований и инициатив Transparency International. Данная организация формирует интегрированные индексы в исследуемой сфере. К наиболее известным относятся индекс восприятия коррупции и индекс взяткодателей. Кроме того, их дополняют индексы международного рейтинга «Барометр мировой коррупции».

Национальным планом противодействия коррупции на 2014 - 2015 годы в п. 2 [3] предусмотрено продолжение проведения среди всех социальных слоев населения в различных регионах страны социологических исследований, которые позволили бы оценить уровень коррупции в Российской Федерации и эффективность принимаемых антикоррупционных мер.

В практике исследования показателей и индикаторов динамики коррупционных нарушений в России в соответствии с отечественными методиками используются различные характеристики.

Фондом ИНДЕМ (Информатика для демократии) и «Национальным антикоррупционным комитетом» исследуется объем коррупционного рынка. Для формирования таких данных анализируется несколько интегрированных показателей, в том числе число обращений лиц, ставших жертвами коррупционных деяний. Это позволяет выявить наиболее коррупционные сферы. На основе объективных и субъективных оценок коррупции формируются сведения об уровне коррупции в России в рамках мероприятий, проводимых Центром сравнительных социологических исследований), Левада-Центром, Фондом «Общественное мнение», Всероссийским центром изучения общественного мнения, Институтом социологии Российской академии наук, Общероссийской общественной организацией малого и среднего предпринимательства ОПОРА России.

Практика исследований в отдельных субъектах Российской Федерации, направленных на выявление показателей и индикаторов динамики коррупционных нарушений в соответствующем регионе, основывается на определении качественных и количественных изменений проявления коррупции. Так, например, в Ярославской области к количественным показателям отнесены доходы, коррупционная активность, частота столкновения с коррупцией, коррупционный риск, охват коррупции, спрос на коррупцию, интенсивность коррупции, средние показатели по стоимости коррупционных услуг с учетом экстремальных значений, степень вовлеченности в коррупцию. Качественные показатели включают коррупционную ситуацию, виды коррупции (бытовая коррупция, деловая коррупция, административная коррупция), коррупционные причины, коррупционные поводы, готовность к коррупционной модели поведения, формы коррупции[4]. При этом следует отметить, что объектом исследования являются сведения о коррупционных деяниях или о состоянии коррупции, полученные из разных источников, в том числе посредством социологических опросов по определению восприятия уровня коррупции населением. Таким образом, выявление различными организациями индикаторов и показателей такого социально-правового явления, как коррупция, основано на исследовании социальной среды, на различных источниках информации.

Успех борьбы с коррупцией зависит от гармоничного развития двух систем контроля - внешней и внутренней. Внутренняя система антикоррупционной профилактики органов власти должна дополняться эффективным внешним контролем со стороны парламента, Счетной палаты и структур гражданского общества. Внешний и внутренний контроль - это система «двух ключей», система «двойного контроля качества» антикоррупционной работы. [5] Разработанная Счетной палатой Российской Федерации Методика оценки эффек- 
тивности антикоррупционных программ [6] построена в трех измерениях: нормативно-правовом, институциональном и так называемом измерении экономической эффективности. В основе лежит система четких и прозрачных индикаторов, которые, если говорить коротко, позволяют объективно оценить, стоит ли полученный результат затраченных на него средств. При этом, как отмечает один из разработчиков данной методики С. В. Степашин, учитываются не только «валовые показатели» (вроде количества коррупционных нарушений или объемов вскрытых финансовых нарушений), но, прежде всего, качественные индикаторы. Среди них можно назвать оценку гражданами уровня коррупции в стране, динамику снижения административных барьеров, степень прозрачности работы государственных и муниципальных органов [7].

Масштабные исследования в сфере противодействия коррупции с учетом сведений, полученных от правоохранительных органов и судебной статистики позволяют оперировать такими данными, как специальный индекс коррупционной пораженности, коэффициент коррупционной пораженности, коррупционная виктимность. Данные показатели основаны на базовом определении «показатели коррупционной пораженности» - абсолютные и относительные показатели, характеризующие объем, интенсивность, структуру, динамику и территориальное распределение коррупционных правонарушений и лиц, их совершивших. [8] Первый из таких показателей - специальный индекс коррупционной пораженности - отношение числа служащих, выявленных в течение определенного периода в связи с совершением коррупционных правонарушений, к общему числу служащих таких служб, органа или подразделения аппарата управления. Второй показатель - коэффициент коррупционной пораженности - число коррупционных правонарушений в течение определенного периода на определенной территории в расчете на 10000 населения, проживающих на данной территории. Третий показатель - коррупционная виктимность - число физических и юридических лиц, подвергшихся в истекший период вымогательству со стороны служащих государственных или негосударственных организаций [9].

Менее масштабными, но не менее важными для планирования и реализации антикоррупционных мероприятий являются данные, полученные в процессе деятельности подразделений по профилактике коррупции на государственной и муниципальной службе. Приведенные ниже индикаторы коррупции могут исчисляться исходя из сведений о коррупционных правонарушениях, выявленных как самими подразделениями, так и в рамках прокурорского надзора за соблюдением законодательства о противодействии коррупции в органах государственной власти или органах местного самоуправления. Наиболее рационально применение данных индикаторов на уровне субъекта РФ или крупного муниципального образования (городской округ, муниципальный район), позволяющих оперировать сведениями о выявленных коррупционных нарушениях в органах власти, входящих в соответствующую систему государственного или муниципального управления. При этом следует учесть, что подразделения по профилактике коррупции в органах власти могут выявлять только те коррупционные правонарушения, которые квалифицируются как дисциплинарные поступки.

Общий индекс коррупционной пораженности органов власти может рассчитываться как отношение числа служащих, выявленных в течение определенного периода в связи с совершением коррупционных правонарушений, к общему числу служащих аппарата органа или органов власти. Коррупционный охват - процент органов власти (или структурных подразделений), в которых выявлены коррупционные нарушения, от общего числа органов власти (или структурных подразделений). Типичность коррупционных нарушений определяется как соотношение видов выявленных коррупционных нарушений к перечню наиболее распространенных их видов, основанных на классификации, применяемой Прокуратурой РФ при осуществлении надзора за соблюдением законодательства о противодействии коррупции. К ним относятся непредставление (представление недостоверных) сведений о доходах, имуществе и обязательствах имущественного характера; нарушение основных обязанностей гражданского служащего; несоблюдение ограничений, связанных с гражданской службой; формирование конкурсных комиссий с нарушением установленных требований, непроведение либо нарушение условий проведения конкурса при поступлении на службу (замещении должности); несоблюдение квалификационных требований к должностям гражданской службы; нарушение основных прав гражданского служащего; несоблюдение требований к служебному поведению гражданского служащего; нарушение запретов, связанных с гражданской службой; принятие нормативных правовых актов, противоречащих федеральному или региональному законодательству; нарушение правил урегулирования конфликта интересов на гражданской службе). [10]Латентность- соотношение количества коррупционных нарушений, выявленных по итогам внешнего контроля (надзора), к количеству самостоятельно выявленных коррупционных нарушений. Наказанность коррупционных наруше- 


\section{Административное и муниципальное право 12 (96) • 2015}

ний- соотношение коррупционных нарушений, по которым назначены дисциплинарные взыскания, с общим числом коррупционных нарушений. Интенсивность коррупционных нарушений - соотношение общего количества выявленных коррупционных нарушений по органам исполнительной государственной власти области, в которых они были выявлены. Динамика коррупционных нарушений - показатель роста (или снижения) выявленных коррупционных нарушений по годам.

Системный анализ таких индикаторов имеет важное значение для выработки адресных мер по противодействию коррупции, оценки эффективности антикоррупционных программ, позволяет определить уровень коррупциогенности конкретного органа власти по отношению к другим органам власти, рационально распределить бюджетные средства на планируемые антикоррупционные мероприятия.

Например, высокий уровень латентности, низкий уровеньнаказанности, типичность коррупционных нарушений вызывает сомнения в эффективности деятельности подразделений по профилактике коррупции в органах государственной власти и органах местного самоуправления. Кроме того, типичность коррупционных нарушений (не- представление (представление недостоверных) сведений о доходах, имуществе и обязательствах имущественного характера) может свидетельствовать о несовершенстве нормативной базы, регулирующей отношения в сфере декларирования доходов, а также методического обеспечения данного процесса. Высокий показатель коррупционного охвата отражает системность проблем в сфере противодействия коррупции, которые следует решать на уровне уполномоченного органа по противодействию коррупции в субъекте Российской Федерации или в муниципальном образовании, а не в конкретном органе власти. Динамика коррупционных нарушений позволяет в целом оценить результативность мероприятий по противодействию коррупции и скорректировать антикоррупционные программы.

Дополнительный эффект от применения индикаторов коррупции в целях ее снижения может быть достигнут за счет того, что и сами государственные и муниципальные служащие, и подразделения по противодействию коррупции в органах государственной власти иместного самоуправления будут осознавать, что «антикоррупционный имидж» конкретного органа власти показателен, измерим и конкретен.

\section{Библиография:}

1. Официальный сайт Центра антикоррупционных исследований и инициатив «Трансперенси Интернешнл - Р» (Центр «ТИ-Р») // URL: http://www.transparency.org.ru/indeks-vospriiatiia-korruptcii/blog

2. Конвенция Организации Объединенных Наций против коррупции // СЗ РФ..2006. N 26. Ст. 2780.

3. Указ Президента РФ от 11.04.2014 г. № 226 «О национальном плане противодействия коррупции на $2014-2015$ годы» // СЗ РФ. 14.04.2014 № 15. Ст. 1729

4. Методика проведения регулярного мониторинга коррупционных проявлений, в том числе на основе взаимодействия с правоохранительными органами Разработана Ярославским государственным университетом им. П.Г. Демидова. Ярославль, 2010 // URL: http://www.yarregio№.ru/depts/ubb/docsPrograms//

5. Степашин С.В. Государственный финансовый контроль в противодействии коррупции // "Журнал российского права".2012.№ 7. Стр.15-17 Официальный сайт Республики Тыва // URL: http:// gov.tuva.ru/content/1364/

6. Модельный закон "Основы законодательства об антикоррупционной политике." Принят в г. Санкт-Петербурге 15.11.2003 Постановлением 22-15 на 22-ом пленарном заседании Межпарламентской Ассамблеи государствучастников СНГ // Информационный бюллетень. Межпарламентская Ассамблея государств-участников Содружества Независимых Государств. 2004. № 33. С. 225-260

7. Государственная политика противодействия коррупции и теневой экономике в России. Монография. Под общей ред. Сулакшина С.С. В 2-х т. М.: Научный эксперт., 2008. С. 435-436

8. Выявление нарушений законодательства о противодействии коррупции средствами прокурорского надзора. Методические рекомендации. Академия Генеральной прокуратуры Российской Федерации. Научно-исследовательский институт. Москва. 2012 // URL: http://www.agprf.org/№ii/№ii-1.html

9. Кабанов П.А. Организационно-правовые аспекты прокурорского надзора за созданием и организацией деятельности Комиссий по соблюдению требований к служебному поведению государственных (муниципальных) служащих и урегулированию конфликта интересов // NB: Административное право и практика администрирования. - 2013. - 1. - С. 1 - 11. DOI: 10.7256/2306-9945.2013.1.405. URL: http://www.e-notabene.ru/al/article_405.html

10. Костенников М.В., Куракин А.В. Административно-правовое противодействие коррупции в системе государственной службы и в деятельности сотрудников полиции Российской Федерации и зарубежных государств. // Полицейская деятельность. - 2011. - 1. - С. 10 - 16.

11. Кабанов П.А. Антикоррупционные программы субъектов Российской Федерации как средства противодействия коррупции: опыт критического анализа // Социодинамика. - 2014. - 5. - С. 42 - 70. DOI: 10.7256/24097144.2014.5.12103. URL: http://www.e-notabene.ru/pr/article_12103.html

12. Куракин А.В. Международное и административное право и противодействие коррупции в системе государственной гражданской службы // NB: Административное право и практика администрирования. - 2014. - 1. - C. 53 - 81. DOI: 10.7256/2306-9945.2014.1.11051. URL: http://www.e-notabene.ru/al/article_11051.html 


\section{References (transliterated):}

1. Ofitsial'nyi sait Tsentra antikorruptsionnykh issledovanii i initsiativ «Transperensi Interneshnl - R» (Tsentr «TI-R») // URL: http://www.transparency.org.ru/indeks-vospriiatiia-korruptcii/blog

2. Konventsiya Organizatsii Ob"edinennykh Natsii protiv korruptsii // SZ RF..2006. N 26. St. 2780.

3. Ukaz Prezidenta RF ot 11.04.2014 g. № 226 «O natsional'nom plane protivodeistviya korruptsii na 2014-2015 gody» // SZ RF. 14.04.2014 № 15. St. 1729

4. Metodika provedeniya regulyarnogo monitoringa korruptsionnykh proyavlenii, $\mathrm{v}$ tom chisle na osnove vzaimodeistviya s pravookhranitel'nymi organami Razrabotana Yaroslavskim gosudarstvennym universitetom im. P.G. Demidova. Yaroslavl', 2010 // URL: http://www.yarregio№.ru/depts/ubb/docsPrograms//

5. Stepashin S.V. Gosudarstvennyi finansovyi kontrol' v protivodeistvii korruptsii // "Zhurnal rossiiskogo prava".2012.№ 7. Str.15-17 Ofitsial'nyi sait Respubliki Tyva // URL: http:// gov.tuva.ru/content/1364/

6. Model'nyi zakon "Osnovy zakonodatel'stva ob antikorruptsionnoi politike." Prinyat v g. Sankt-Peterburge 15.11.2003 Postanovleniem 22-15 na 22-om plenarnom zasedanii Mezhparlamentskoi Assamblei gosudarstv-uchastnikov SNG // Informatsionnyi byulleten'. Mezhparlamentskaya Assambleya gosudarstv-uchastnikov Sodruzhestva Nezavisimykh Gosudarstv. 2004. № 33. S. 225-260

7. Gosudarstvennaya politika protivodeistviya korruptsii i tenevoi ekonomike v Rossii. Monografiya. Pod obshchei red. Sulakshina S.S. V 2-kh t. M.: Nauchnyi ekspert., 2008. S. 435-436

8. Vyyavlenie narushenii zakonodatel'stva o protivodeistvii korruptsii sredstvami prokurorskogo nadzora. Metodicheskie rekomendatsii. Akademiya General'noi prokuratury Rossiiskoi Federatsii. Nauchno-issledovatel'skii institut. Moskva. 2012 // URL: http://www.agprf.org/№ii/№ii-1.html

9. Kabanov P.A. Organizatsionno-pravovye aspekty prokurorskogo nadzora za sozdaniem i organizatsiei deyatel'nosti Komissii po soblyudeniyu trebovanii k sluzhebnomu povedeniyu gosudarstvennykh (munitsipal'nykh) sluzhashchikh i uregulirovaniyu konflikta interesov // NB: Administrativnoe pravo i praktika administrirovaniya. - 2013. - 1. - C. 1 - 11. DOI: 10.7256/2306-9945.2013.1.405. URL: http://www.e-notabene.ru/al/article_405.html

10. Kostennikov M.V., Kurakin A.V. Administrativno-pravovoe protivodeistvie korruptsii v sisteme gosudarstvennoi sluzhby i v deyatel'nosti sotrudnikov politsii Rossiiskoi Federatsii i zarubezhnykh gosudarstv. // Politseiskaya deyatel'nost'. 2011. - 1. - C. $10-16$.

11. Kabanov P.A. Antikorruptsionnye programmy sub"ektov Rossiiskoi Federatsii kak sredstva protivodeistviya korruptsii: opyt kriticheskogo analiza // Sotsiodinamika. - 2014. - 5. - C. 42 - 70. DOI: 10.7256/2409-7144.2014.5.12103. URL: http://www.e-notabene.ru/pr/article_12103.html

12. Kurakin A.V. Mezhdunapodnoe i administrativnoe pravo i protivodeistvie korruptsii v sisteme gocudapctvennoi grazhdanskoi sluzhby // NB: Administrativnoe pravo i praktika administrirovaniya. - 2014. - 1. - C. 53 - 81 . DOI: 10.7256/2306-9945.2014.1.11051. URL: http://www.e-notabene.ru/al/article_11051.html 